\title{
The way to reach the gold standard in dental surgery: Integrated Surgical Studio Design KYRI
}

When I went to the Cologne Dental Exhibition, IDS 2017, I still had in mind the surgery room at the University Dentistry Hospital where I had had my practical training in oral surgery. WHO estimates that dental treatments cause significant stress in over $30 \%$ of patients. Their being afraid of the dentist and of the pain caused is much higher in the case of oral surgery or oral implantology.

While at the IDS 2017, out of the many dental pieces of equipment we noticed at the Tecno-Gaz S.p.A stand (I43038 Sala Baganza (PR), Italy), the Integrated Surgical Studio Design called KYRI was the most innovative. It is the concept of dental ergonomics for the dental surgery room, a new way of conceiving space, which provides:

1. Professionalism: provides the best possible working way that allows you to achieve true potential.

2. Modularity: organizes space according to personal needs, clinical needs and the patient's perception.

3. Versatility: space can adapt, develop, change according to your ideas and opportunities.

4. Welcoming: your space conveys positivity, cleanliness and visual appeal, and at the right time it can turn into a surgical room.

5. Integrated: space conceived and organized according to labor ergonomics, ensuring efficiency and productivity.

6. Uniqueness: you are different from your colleagues, work differently and have different habits even if you perform similar treatments.

Here are the components of the Integrated Surgical Studio KYRI Design:

- KYRI UNIT for long-term dental and surgical treatment, a perfect combination of an operating table and a dental chair, with four engines that provide 5-axis movements, and a 3D motion orbital headrest. It allows a level of flexibility that cannot be achieved in a common dental chair. It has an advanced electronic position control system controlled by a wireless pedal. It is equipped with pressure sensors to adapt via the Human Pressure Spot Compensation System to the patient's anatomical structure.

- $\quad$ KYRI CART with maximum instrumental freedom through 5 slots that allows the dentist to perform from regular surgery to implants, equipped with two powerful micromotors, one of which is for implantology with a peristaltic pump and torque adjustment. All controls are placed under the membrane, allowing fast cleaning and hygiene. It has a separate power supply that ensures total operating autonomy and allows the continuous use of disinfectant solutions or special instrument liquids.

- $\quad$ KYRI WATER UNIT turns the dental surgery into a multifunctional integrated one allowing cleaning and control of the surgical suction thanks to the cannula support with two cannulae.

- $\quad$ KYRI DSS, a sophisticated surgical vacuum cleaner that fully meets the dental surgery requirements with reduced noise: $46.4 \mathrm{~dB}$.

The Integrated Surgical Studio Design KYRI also includes some smart trolleys designed for the needs of modern dental surgery and professional work chairs.

In Italy, I had the opportunity to work in a clinic equipped with an Integrated Surgical Studio Design KYRI. Allow me to share the impact and the impression I have been left with:

- $\quad$ non-traumatic visual impact helps the patient overcome the classic fear of dental surgery.

- maximum harmony and perception of the highest quality.

- $\quad$ maximum flexibility for any treatment

Let me assure you that your patients and your clinical team deserve to have the satisfaction of working in a unique technological environment.

Florin - Eugen Constantinescu

DMD, PhD Student

Editorial Director, Product News

DOI: 10.25241/stomaeduj.2018.5(2).prodnews.1

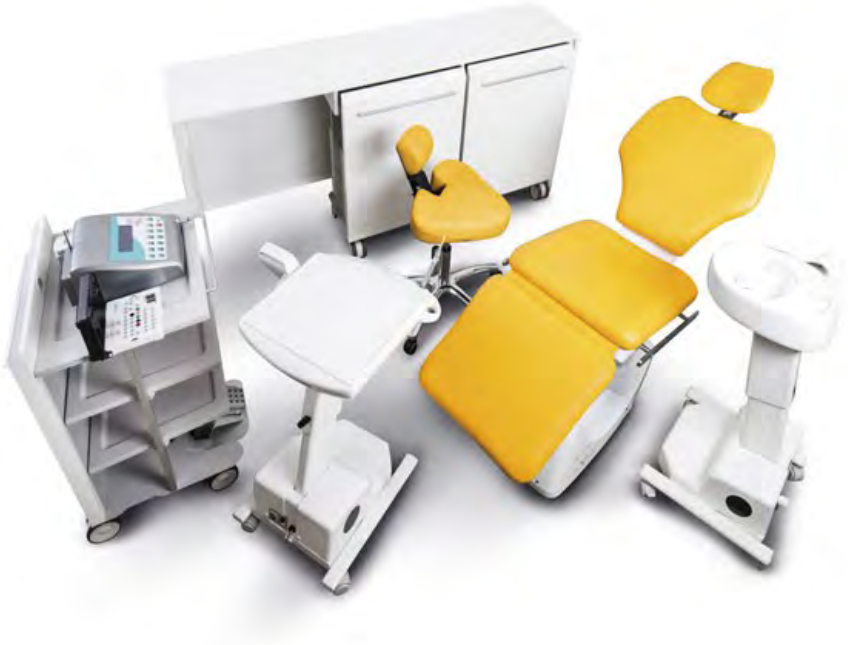

The Integrated Surgical Studio Design KYR

(Tecno-Gaz S.p.A., I-43038 Sala Baganza (PR), Italy)

http://www.tecnogaz.com/en/Surgical-furniture/integrated-surgical-studio-design.aspx 